\title{
Clinical computed tomography and surface-enhanced Raman scattering characterisation of ancient pigments
}

\author{
Sveva Longo ${ }^{1,2}$, Silvia Capuani ${ }^{2}$, Francesca Granata ${ }^{3}$, Fortunato Neri ${ }^{1}$, Enza Fazio ${ }^{1}$ \\ ${ }^{1}$ Department of Mathematical and Computational Sciences, Physics Science and Earth Sciences (MIFT), University of Messina, Viale F. \\ Stagno D'Alcontres, 98166 Messina, Italy. \\ ${ }^{2}$ Nuclear Magnetic Resonance and medical physics Laboratory CNR-ISC, Department of Physics, Sapienza University of Rome, Piazzale Aldo \\ Moro 5, 00185 Roma, Italy. \\ ${ }^{3}$ Neuroradiology Unit-Department of Biomedical Sciences and Morphological and Functional Images (BIOMORF), University of Messina, Via \\ Consolare Valeria 1, 98125 Messina, Italy.
}

\begin{abstract}
A systematic and complete chemical and physical characterisation of painted pigments on wood samples was carried out using multislice X-ray computed tomography (MSCT) and surface-enhanced Raman scattering (SERS) techniques. Inorganic and organic pigments present on the wooden tablets were differentiated by MSCT determinations of Hounsfield units, a semi-quantitative method for measuring Xray attenuation that, in turn, offers an indirect estimation of a material's density. However, the MSCT technique is not as reliable as traditional spectroscopic techniques for recognising and classifying organic pigments. Nevertheless, a strength of the MSCT approach was its ability to simultaneously provide a volumetric view of the wood and segment the layers of the specimen using suitable reconstruction methods such as is generally done for biomedical applications. Furthermore, the SERS technique made it possible to identify the type of material present in the pigments (for both inorganic or organic materials) with a high spatial resolution, even pigments in mixtures or those applied directly on the investigated wooden support. The combined MSCT and SERS data obtained through this systematic investigation constitutes the basis for the assembly of larger reference databases that will ultimately support the development of long-term conservation protocols.
\end{abstract}

\section{Section: RESEARCH PAPER}

Keywords: X-ray computed tomography; Hounsfield units; SERS; FTIR; optical absorbance; ancient pigments; conservation science

Citation: Sveva Longo, Silvia Capuani, Francesca Granata, Fortunato Neri, Enza Fazio, Clinical computed tomography and surface-enhanced Raman scattering characterisation of ancient pigments, Acta IMEKO, vol. 10, no. 1, article 4, March 2021, identifier: IMEKO-ACTA-10 (2021)-01-04

Editor: Eulalia Balestrieri, University of Sannio, Italy

Received March 24, 2020; In final form August 25, 2020; Published March 2021

Copyright: This is an open-access article distributed under the terms of the Creative Commons Attribution 3.0 License, which permits unrestricted use, distribution, and reproduction in any medium, provided the original author and source are credited.

Funding: This work was supported by PO FSE Regione Siciliana 2014-2020.

Corresponding author: Sveva Longo, e-mail: sveva.longo@unime.it

\section{INTRODUCTION}

The identification and characterisation of pigments provide essential information for the dating, authentication and conservation of wood-based objects and for the study of art history in general [1], [2]. Spectroscopic techniques are typically used to characterise pigments. However, different methods are used to describe inorganic and organic pigments due to the intrinsic limitations of the techniques: X-ray fluorescence cannot provide a definitive elemental signature; Fourier transform infrared spectroscopy is limited by the interference of binders and extenders [3] and high-performance liquid chromatography [4] requires relatively large samples $(0.5-5 \mathrm{~mm}$ in diameter). In the last few years, portable Raman setups have regularly been used to study a wide variety of materials, including paper, in order to follow degradation processes or create spectral reference libraries of organic and inorganic pigments. However, some laser source wavelength is absorbed by specific pigments, leading to extensive fluorescence backgrounds, which obscure the weak Raman signals, or in worse cases, cause photo-degradation of the sample, preventing pigment identification [5]. Surface-enhanced Raman scattering (SERS) addresses these difficulties since the presence of noble metal nanoparticles induces a giant amplification of the Raman signal [6].

Clinical computed tomography based on multislice technology (MSCT), which has been used for decades in the medical field, can be successfully applied for the localisation of 
structures on or under the painting's surface [7] without removing the paint or scratching the surface of the wood. MSCT can also be used for densitometric estimation, which is expressed in Hounsfield units (HU).

In the biomedical field, the density values of different structures and tissues in the human body and their variations have been estimated primarily through the use of MSCT techniques. Specifically, using MSCT scans, it is possible to reconstruct images through two main techniques: 2D images can be generated using multiplanar reconstruction (MPR), and 3D models can be generated using volume rendering technique (VRT). The VRT images are generated using 3D filters calibrated with reference to known densities (measured in $\mathrm{HU}$ ) (e.g. of various human body tissues). The technique is used by medical doctors to navigate inside a human body virtually. Using VRT reconstruction, it is possible to select a specific density and virtually erase the others. In this way, an object can be virtually dissected and studied from every angle [8].

Nevertheless, there are some limitations, which are primarily related to the minimum slice thickness ( $0.6 \mathrm{~mm}$ in our case), although the newest generation of Siemens computer tomography (CT) scanners have a spatial resolution of $0.2 \mathrm{~mm}$, and we think that this capability will continue to improve. The gantry opening can also be a limiting factor; the maximum size available on the market is $78 \mathrm{~cm}$ in diameter. With an opening of this size, the method can be applied to small and medium-size objects, which includes the majority of artefacts. Moreover, the widespread international adoption of this instrumentation makes it possible to carry out this type of analysis in any city, and scans can be completed very quickly (only $12 \mathrm{~s}$ per scan). For these reasons, improvements to this method should be explored to make this innovative, valuable and useful tool more available for cultural heritage investigations.

In this paper, clinical CT and its dedicated software (designed for medical use) were used for the first time to systematically investigate the microstructure of two wooden tablets painted with ancient pigments in accordance with Cennino Cennini's instructions [9]. CT analyses were used to investigate the status of the wood and, in particular, to provisionally classify the detected pigments. However, we found that some of the identifications made using the $\mathrm{HU}$ values (indirect indices of the pigment densities determined according to conventional approaches) were not realistic. Therefore, the combination of MSCT and spectroscopic analyses was used to ensure accurate identification. In particular, Raman/SERS investigations were used to confirm the dubious results of the MSCT analysis with regard to organic pigments that were present on the tablets, especially those at low concentrations. For correct identification, SERS spectra of several varieties of pigments were acquired as references. In this way, we discriminated the various pigments and identified their regular contribution on wooden tablets.

\section{MATERIALS AND METHODS}

\subsection{Sample preparation}

Two chestnut oak (Castanea sativa) wooden tablets measuring $33 \times 14 \mathrm{~cm}^{2}$ and painted with inorganic and organic pigments from Zecchi Florence were investigated [10]. The pigments we used were red ochre, natural ultramarine, white lead, cinnabar, madder lake, malachite, red lead and azurite. Rabbit skin tempera glue was chosen as a binder, and two types of wooden support were utilised, one prepared with Bologna plaster and one prepared with incamottatura, which was widely used on wooden paintings in the $11^{\text {th }}$ to the $14^{\text {th }}$ centuries and consists of a layer of linen canvas applied on the wooden support to simplify the colour expanse.

\subsection{Multislice computed tomography}

In our experiments, a Somatom Sensation 16 MSCT (Siemens Healthcare) with a $70 \mathrm{~cm}$ gantry opening located in the Neuroradiology Unit-Department of Policlinic G. Martino of Messina was used (Figure 1).

A CT scanner is composed of three units (Figure 2): 1 - the scanning unit (gantry) in which the high voltage generator, $\mathrm{X}$-ray tube, collimation system, detectors and data acquisition system are collocated, 2 - the computers used to scan and reconstruct the data and 3 - the control console, comprising systems for the display, storage and playback of images.

After the acquisition parameters were optimised to obtain well-resolved images, all of the MSCT images were acquired using the following parameters: $62 \mathrm{~mA}, 120 \mathrm{kV}$ and B60f smooth kernel. A $0.6 \mathrm{~mm}$ slice thickness was used in order to obtain the highest resolution. The kernel number determines the sharpness of the edges and the smoothness of the images. In our case, we used soft tissue algorithms performed with a kernel setting of $20-40$, and bone algorithms, which use a 60 or 70 kernel setting. These settings were chosen because bones and soft tissues have characteristics similar to wood. Thus, we expected that a low kernel setting (smoother image) would generate good contrast resolution, a low noise level and poor edge definition, as happens in biomedical diagnosis. Moreover, a higher number of kernels (sharper image) should provide better spatial resolution, a higher noise level and better edge definition [11].

The resulting images were evaluated using MPR, VRT and Siemens SYNGO Software. Several regions of interest were selected on the MPR images, and the HU mean values of the pigments were estimated. During VRT imaging post-processing, different CT medical filters with densitometric characteristics close to those of our materials, such as those for tissue and skin, were explored. It was expected (as already proved with preliminary tests) that conventional densiometric similarities between wood and tissues would correspond to analogous

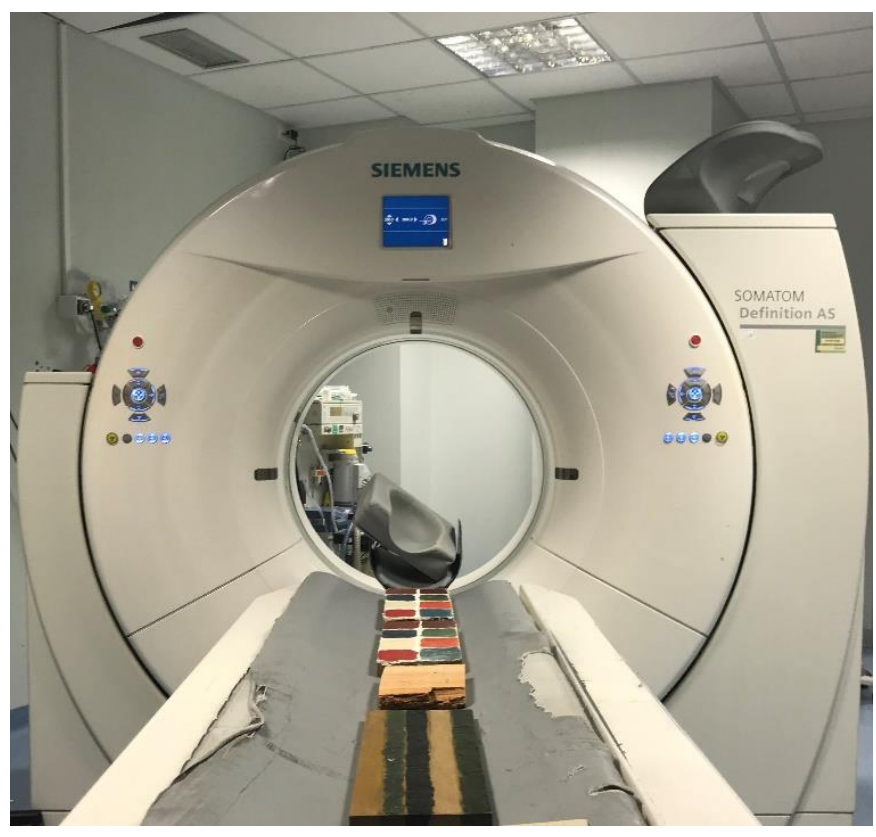

Figure 1. Wooden tablets painted with the most commonly used ancient pigments placed on the CT scanner bed for MSCT scanning. 


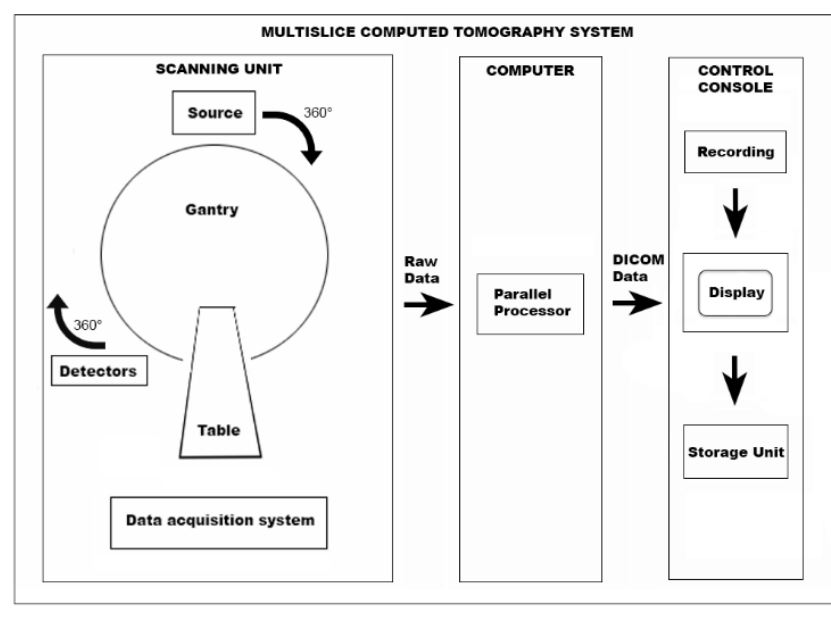

Figure 2. Multislice computed tomography schema.

behaviour in terms of attenuation of the X-ray beam during CT characterisations. A further advantage of MSCT is the short time needed to perform image scans. As it was developed for human analysis, it was designed to generate quality images quickly. For example, images of organs are acquired in 1 second, those of the heart in 5 seconds and those of the whole body in less than 10 seconds [12]. Longer scans do not improve measurements because the technique is not time dependant. In this study, we scanned the two wood specimens in 12 seconds.

The most important innovation that follows from this method is the possibility of estimating the different densities of materials through attenuation measurements [13]. Attenuation, which measures the decrease in X-ray beam intensity as it passes through matter, is the most crucial parameter of MSCT. This reduction in X-ray intensity is a consequence of absorption, deflection or scattering processes, and, thus, it is affected by several different factors including the beam energy, the atomic number of the absorber and the thickness of the scanned object.

The measurement of the electron density is made using the Hounsfield scale, expressed in HU, which includes 2001 different shades of grey, from black to white. The HU scale is a linear transformation of the original linear attenuation coefficient measurement into one in which the radiodensity of distilled water at standard pressure and temperature is defined as $0 \mathrm{HU}$, while the radiodensity of air at standard pressure and temperature is defined as $-1000 \mathrm{HU}$ and the radiodensity of bone is set to $+1000 \mathrm{HU}$. Therefore, for any material with linear attenuation coefficient $\mu$, the corresponding $H U$ value is given by

$$
H U=1000 \times \frac{\mu-\mu_{\mathrm{w}}}{\mu_{\mathrm{w}}-\mu_{\mathrm{air}}},
$$

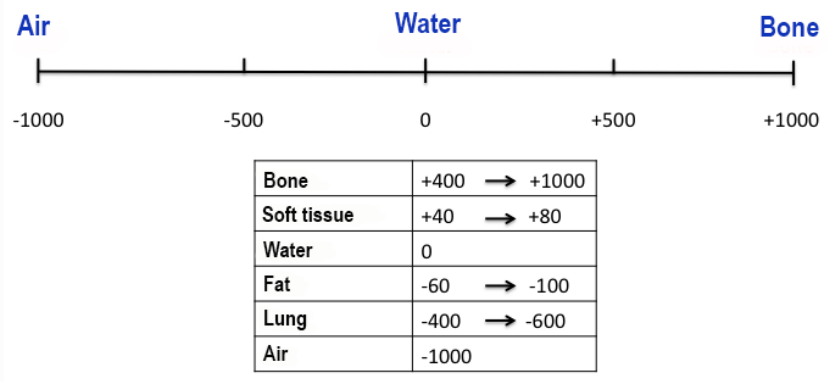

Figure 3. Hounsfield unit scale. where $\mu_{\mathrm{w}}$ and $\mu_{\text {air }}$ are the linear attenuation coefficients of water and air, respectively; consequently, the Hounsfield unit is a relative parameter in which water is taken as a reference substance (Figure 3).

\subsection{Spectroscopic techniques: UV-vis optical absorption, Fourier transform infrared spectroscopy and surface- enhanced Raman scattering}

UV-vis optical absorption spectra were obtained using the PerkinElmer Lambda 750 UV/VIS/NIR spectrometer in the 190-1100 nm range. Spectra were acquired at room temperature in a few minutes, and each measurement was conducted twice to test its repeatability.

UV-vis optical absorption spectra of $\mathrm{Au}$ colloids were acquired three times: immediately after the ablation process using quartz cuvettes, one day after this to monitor their stability over time and, finally, after the Au substrates were soaked in the pigments.

FTIR spectra were collected at room temperature using a PerkinElmer Spectrum 100 spectrometer in the $450-4000 \mathrm{~cm}^{-1}$ range. The spectrometer was used in an attenuated total reflectance (ATR) configuration. Powdered pigments were used as a reference, and pigments painted on the wooden support were analysed without any treatment of the samples. They were placed directly on the ATR support. FTIR data were collected in a few minutes, and the resulting spectra were the average of ten acquisitions.

To carry out the SERS analysis, gold (Au) nanocolloids were prepared using a green laser ablation synthesis procedure [14] and deposited on glass and silicon substrates. SERS spectra were acquired after the Au substrates were soaked in pigments such as pure alizarin, carmine lake and purpurin solutions at different concentration levels (between $10^{-3}$ and $10^{-5} \mathrm{M}$ ) for about $1 \mathrm{~h}$ and then rinsed with deionised water and left to dry in air. Each sample shows a specific molecular fingerprint and a high homogeneity, which was confirmed by performing measurements on a $60 \times 60 \mu \mathrm{m}^{2}$ surface area. After the acquisition of the Raman spectra of the powdered pigments used as references, SERS measurements were carried out on the painted wooden tablets. Raman spectra were collected at room temperature using a Horiba XploRA spectrometer. The diode lasers were focused on a $50 \mu \mathrm{m}$ diameter spot with a power of about $1.4 \mathrm{~W}$ and $0.5 \mathrm{~W}$ for $532 \mathrm{~nm}$ and $785 \mathrm{~nm}$ excitations, respectively. The integration time for each measurement was 80 and $150 \mathrm{~s}$, with an accumulation time of $3 \mathrm{~s}$.

\section{RESULTS AND DISCUSSION}

\subsection{Multislice computed tomography data analysis}

In Table 1, the HU values estimated by MSCT and the density in $\mathrm{g} / \mathrm{cm}^{3}$ reported in [15] of the investigated pigments are presented.

Most of the investigated pigments are inorganic and made with metallic oxide. For example, white lead is made from basic lead carbonate $\left[2 \mathrm{PbCO}_{3} \cdot \mathrm{Pb}(\mathrm{OH})_{2}\right]$ and has a radiodensity of about $2852 \mathrm{HU}$, the highest value of the studied samples. Red lead $\left(2 \mathrm{PbO} \cdot \mathrm{PbO}_{2}\right)$ is also made from lead, but, due to its different chemical coordination, it has a radiodensity of $1456 \mathrm{HU}$. The radiodensities of the other samples can be listed in descending order as follows: $1534 \mathrm{HU}$ for cinnabar; $775 \mathrm{HU}$ for red ochre; $674 \mathrm{HU}$ for malachite; $356 \mathrm{HU}$ for azurite; $297 \mathrm{HU}$ for natural ultramarine and, finally, $218 \mathrm{HU}$ for madder lake. As shown in Figure 4, all of these values closely follow the density trend 
Table 1. Nomenclature, chemical formula, density and HU values of the pigments painted on the wooden support.

\begin{tabular}{cccc}
\hline Pigments & Chemical formula & $\begin{array}{c}\text { Density } \\
\left(\mathbf{g} / \mathbf{c m}^{3}\right)[\mathbf{1 5}]\end{array}$ & HU Values \\
\hline Madder Lake & $\mathrm{C}_{14} \mathrm{H}_{8} \mathrm{O}_{4}$ or $_{14} \mathrm{H}_{8} \mathrm{O}_{5}$ & 1.5 & 218 \\
Ultramarine & $\mathrm{Na}_{7} \mathrm{Al}_{6} \mathrm{Si}_{6} \mathrm{O}_{24} \mathrm{~S}_{3}$. & 2.4 & 297 \\
Azurite & $\mathrm{Cu}_{3}\left(\mathrm{CO}_{3}\right)_{2}(\mathrm{OH})_{2}$. & 3.8 & 356 \\
Malachite & $\mathrm{Cu}_{2} \mathrm{CO}_{3}(\mathrm{OH})_{2}$ & 3.8 & 674 \\
Red Ochre & $\propto-\mathrm{Fe}_{2} \mathrm{O}_{3}$ & 5.3 & 775 \\
Red Lead & $2 \mathrm{PbO}^{2} \mathrm{PbO}_{2}$ & 8.2 & 1456 \\
Cinnabar & $\mathrm{HgS}$ & 8.2 & 1534 \\
White Lead & $2 \mathrm{PbCO}_{3} \cdot \mathrm{Pb}(\mathrm{OH})_{2}$ & 11.37 & 2852 \\
\hline
\end{tabular}

estimated by conventional methods (Jolly balance, beam balance, pycnometer and heavy liquids). As expected, higher density values correspond to higher $\mathrm{HU}$ values. Moreover, metals are in the positive range of $\mathrm{HU}$ values starting from $1500 \mathrm{HU}$.

However, some materials of equal density have different $\mathrm{HU}$ values. This experimental evidence demonstrates an added value provided by MSCT technique. For example, cinnabar and red lead have the same density, but their radiodensities are $8.2 \mathrm{HU}$ and about $1500 \mathrm{HU}$, respectively. Similarly, azurite and malachite both have a density of $3.8 \mathrm{~g} / \mathrm{cm}^{3}$, but they have different radiodensities (356 and $674 \mathrm{HU}$, respectively). In this case, however, the observed differences were probably due to inhomogeneities in the pigment layer measuring less than $0.6 \mathrm{~mm}$ (less than the CT slice thickness). Azurite is less opaque than malachite, and it is probable that the concentration of azurite in its measured area was less than the corresponding concentration of malachite.

Finally, a drawback of MSCT must be mentioned. The estimated HU values of madder lake are not realistic, and this can be explained by considering the underlying mechanisms of the MSCT technique. Attenuation coefficient values are affected by the absorption and scattering of the incident radiation. At the $\mathrm{X}$ ray energy level used in our CT investigation, $120 \mathrm{keV}$, a competition between Compton scattering (which results in incoherent scattering for elements of $Z<20$ ) and photoelectric absorption (which increases for $Z>20$ ) occurs. Thus, the influence of these mechanisms seems relevant when considering organic pigments such as madder lake. The madder lake value was also invalidated by the presence of calcium sulphate hydrate

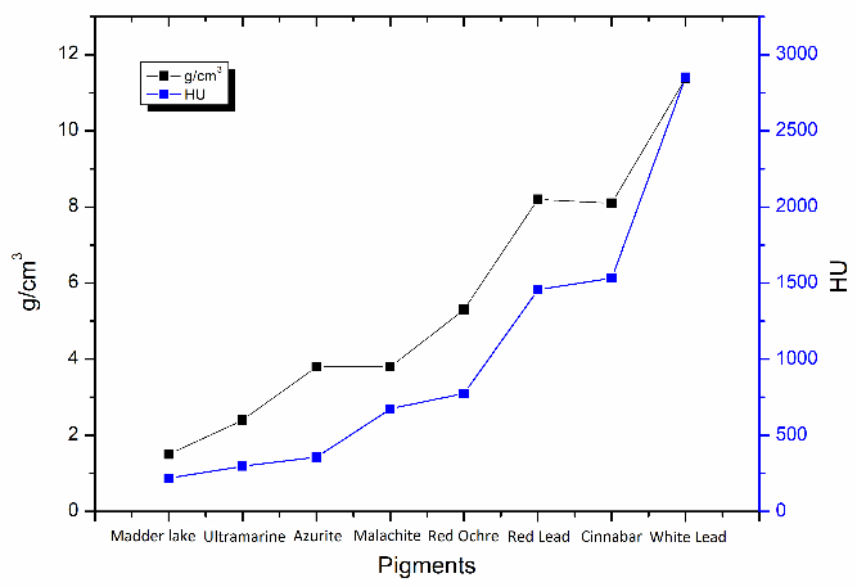

Figure 4. HU values and density expressed in $\mathrm{g} / \mathrm{cm}^{3}$ for all the detected pigments on the wooden tablets.

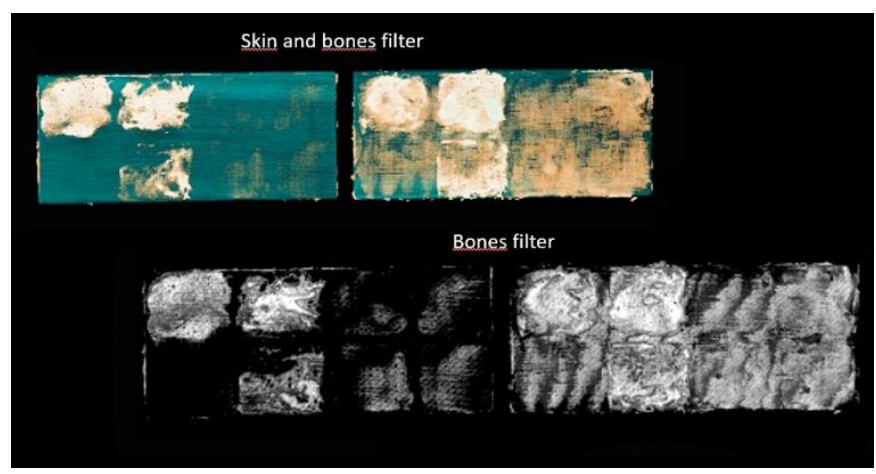

Figure 5. MSCT results after processing with VRT filters. a) skin and bone filter, b) bone filter.

(Bologna plaster), which was used during the sample preparation and has a density of around $2.9 \mathrm{~g} / \mathrm{cm}^{3}$.

In this work, we chose medical VRT filters calibrated on the human body that include density values similar to those of the investigated materials. The upper panel of Figure 5 shows a virtual map of all of the materials present on the samples. This map was obtained using skin and bone VRT filters, which divide the sample into white zones (pigments based on lead and mercury), blue zones (wood) and peach zones (linen canvas and organic substances). The second filter that was used, a bone filter, highlights the pigments only (bottom panel of Figure 5), especially those with densitometric $\mathrm{HU}$ values closest to the HU value of bone $(+1000 \mathrm{HU})$ (see also Table 1$)$.

The third filter that was used is typically applied for evaluating the pulmonary system. This filter was selected because wood is a very porous material that contains a lot of air (see Figure 6). In this case, the densitometric values are on the negative range of the HU Scale, since the HU value of air is -1000 . For example, the radiodensity of chestnut oak wood was measured as -300 HU.

Densitometric measurements were also performed on treerings, and investigations of latewood and earlywood found radiodensities of $-157 \mathrm{HU}$ and $-459 \mathrm{HU}$, respectively. Latewood has a greater radiodensity than earlywood, lung tissue or air, and of these materials its radiodensity is the closest to that of water $(0 \mathrm{HU})$. This finding is in agreement with the microstructural features of growth rings, as latewood is stronger and more compact than earlywood [15]. The average radiodensity of the latewood and earlywood regions is about $-300 \mathrm{HU}$, which corresponds to the total HU value of chestnut oak.

To summarise, MSCT was able to provide qualitative information about materials on wood specimens. In detail, the application of MSCT to a cultural heritage object made it possible to 1) view structures, 2) understand the manufacturing method, 3) recognise subsequent restoration, 4) assess the conservation status of the object and its materials (for example, tunnels caused by xylophagous insects were perfectly visible) and 5) in the case of wooden artefacts, identify the types of wood used and perform dendrochronological analysis [16]. MPR reconstruction allowed us to identify the different pigments by mapping $\mathrm{HU}$ values corresponding to $\mathrm{X}$-ray coefficient attenuation onto the known density of each material [17]. In addition, VRT filters can be used to virtually dissect objects without compromising their integrity. This approach made it possible to obtain details that, in some cases, were not visible and to generate a complete map of all of the materials on the artefacts. It is important to emphasise 

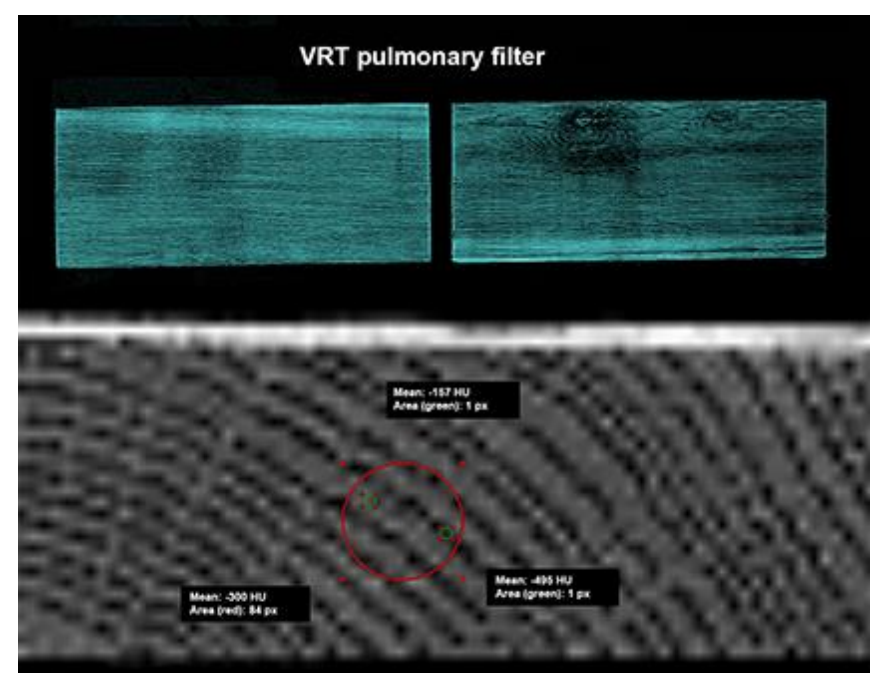

Figure 6. a) Results of VRT pulmonary filter application (top), b) MPR image showing the points at which densitometric wood measurements were carried out (bottom).

that this type of discrimination could be extended to any other kind of material found on artistic objects.

\subsection{Analysis of the UV-vis optical absorption and Fourier transform infrared spectroscopy data}

The UV-vis optical absorption spectra of some of the powder samples are shown in Figure $7 \mathrm{a}-\mathrm{d}$. The analysed samples show similar UV-visible absorption spectra characterised by a structured band located between 400 and $700 \mathrm{~nm}$. The different chromophores cannot be discriminated and, thus, cannot be ascribed to a specific pigment. Only carmine lake powder shows two defined absorption features at about $300 \mathrm{~nm}$ and $370 \mathrm{~nm}$ as well as a structured group in the $400-600 \mathrm{~nm}$ range. These bands are probably due to the different acid-base forms of carminic acid when it is dispersed in water (as was true in our case): CA, $\mathrm{CA}^{-}, \mathrm{CA}^{2-}, \mathrm{CA}^{3-}$ and $\mathrm{CA}^{4-}[18]$.

Figure $7 \mathrm{e}-\mathrm{g}$ shows the FTIR spectra of dyes on the painted tablets. Figure 7 displays a prominent feature at about $1400 \mathrm{~cm}^{-1}$ and two well-defined contributions at around $1600 \mathrm{~cm}^{-1}$, which is similar to the spectra of pure white lead inorganic pigment [19],
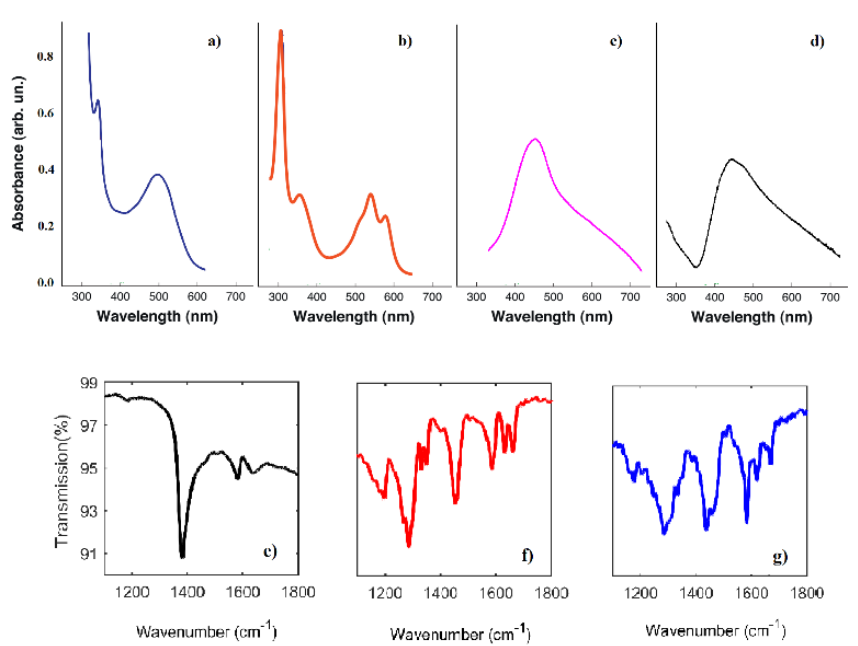

Figure 7. a-d) UV-vis absorption spectra of nominal cinnabar, carmine lake, red lead and malachite powders, e-g) FTIR spectra of pigments on tablets. Some FTIR contributions could also be ascribed to features of wood, such as lignin $\left(1275 \mathrm{~cm}^{-1}\right)$ and cellulose-hemicellulose $\left(1650 \mathrm{~cm}^{-1}\right)$. while the bands in Figure $7 \mathrm{f}$ and $\mathrm{g}$ are similar to those ascribed to copper carbonates and previously observed for azurite and malachite [20]. Finally, the FTIR spectra of cinnabar (not shown) is analogous to spectra reported in [21]. The infrared analysis detected complex fingerprints in all of the samples. Some FTIR contributions are due to features of wood, such as lignin (around $1275 \mathrm{~cm}^{-1}$ ) and cellulose-hemicellulose (around $1650 \mathrm{~cm}^{-1}$ ). Hence, it is not possible to completely differentiate the pigments using only UV-vis optical absorption and FTIR spectra. MicroRaman analysis provided information to complement the complex results of FTIR. Raman spectroscopy has an advantage over FTIR when identifying pigments in painted wooden tablets. Both organic and inorganic paints can be infrared active, but their absorptions are so low that it is difficult to distinguish between two samples using only the IR spectra. However, pigments show a strong response in the Raman spectra, especially below $600 \mathrm{~cm}^{-1}$, where IR does not strongly absorb. The ability to detect these low-frequency vibrations makes Raman spectroscopy a useful tool for differentiating pigments in painted tablets. Furthermore, Raman spectroscopy has another advantage over FTIR. Since the Raman peaks are sharp and do not overlap, it is much easier to resolve mixtures of pigments using Raman spectroscopy rather than FTIR. Also, the technique is sensitive to even small differences in the intensities of various peaks. Since paints are a complex mixture of many components, Raman spectroscopy can be used to distinguish between two similar paint samples that have slightly different amounts of each component.

\subsection{Analysis of Raman spectroscopy and surface-enhanced Raman spectroscopy data}

Figure 8 shows the Raman spectra of nominal malachite, cinnabar and red lead powders, used as references for a subsequent comparison with Raman spectra collected on the painted tablets. The spectra plotted in red in Figure 7a shows the characteristic bands of malachite [22], [23] (see also Table 2) together with the typical features, centred at 1300 and $1600 \mathrm{~cm}^{-1}$, of carbon black. In the $300-550 \mathrm{~cm}^{-1}$ range shown in Figure $8 \mathrm{~b}$, the Raman spectrum is characterised by features typical of red lead [mixed $\mathrm{Pb}$ (II) and $\mathrm{Pb}$ (IV) oxide with the general formula
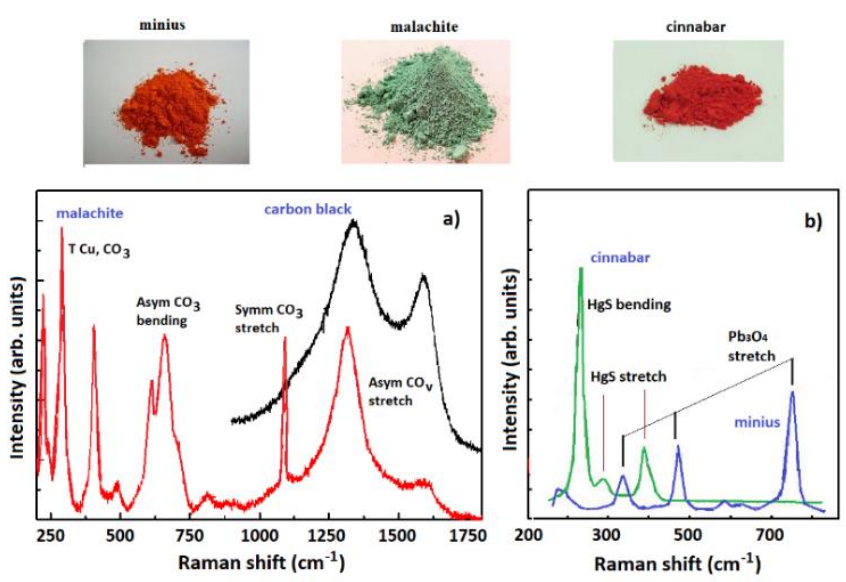

Figure 8. Raman spectra of nominal malachite, cinnabar and red lead powders. The spectra plotted in red (panel a) shows the characteristic bands of malachite, whose assignments are reported in Table 2 . In some points of the same powder, the typical Raman bands of a carbon black material have been collected. The Raman spectra shown in panel $b$ are characterised by a mixed $\mathrm{Pb}$ (II) and $\mathrm{Pb}$ (IV) oxide phase and by the typical HgS stretching modes, which are constituents of red lead and cinnabar, respectively [24], [25]. 
Table 2. Positions $\left(\mathrm{cm}^{-1}\right)$ and assignments of Raman bands typical of malachite [24], [25].

\begin{tabular}{|c|c|c|}
\hline \multicolumn{3}{|c|}{ Malachite } \\
\hline Frost et al. (2002) & Mattei et al. (2008) & Assignments \\
\hline $\begin{array}{c}130,142,151,166,176, \\
205,217,249,267,294, \\
320,389,429,514,531 \\
563,596\end{array}$ & $\begin{array}{c}157,171,182,204,224 \\
272,352,435,513,537 \\
601\end{array}$ & $\mathrm{TCu}, \mathrm{CO}_{3}$ \\
\hline $\begin{array}{l}718 \\
750\end{array}$ & $\begin{array}{l}723 \\
753\end{array}$ & $\begin{array}{l}\mathrm{V}_{4}-\text { Asymmetric } \mathrm{CO}_{3} \\
\text { bending mode }\end{array}$ \\
\hline $\begin{array}{l}807 \\
817\end{array}$ & & $\begin{array}{l}\mathrm{v}_{2} \text {-Symmetric } \mathrm{CO}_{3} \\
\text { bending mode }\end{array}$ \\
\hline 1098 & $\begin{array}{l}1058 \\
1101\end{array}$ & $\begin{array}{l}\mathrm{v}_{1}-\text { Symmetric } \mathrm{CO}_{3} \\
\text { stretching mode }\end{array}$ \\
\hline $\begin{array}{l}1365 \\
1423 \\
1493 \\
1514\end{array}$ & $\begin{array}{l}1370 \\
1463 \\
1497\end{array}$ & $\begin{array}{l}\mathrm{V}_{3}-\text { Asymmetric } \mathrm{CO}_{v} \\
\text { stretching mode }\end{array}$ \\
\hline & & $\mathrm{O}-\mathrm{H}$ bending mode \\
\hline $\begin{array}{l}3349 \\
3380\end{array}$ & 3380 & $\mathrm{O}-\mathrm{H}$ stretching mode \\
\hline
\end{tabular}

$\mathrm{Pb}_{3} \mathrm{O}_{4}$ ] [24]. Finally, the Raman spectra plotted in green in Figure $8 \mathrm{~b}$ displays prominent bands at about 278,290 and $353 \mathrm{~cm}^{-1}$, which are assigned to $\mathrm{HgS}$ bending and stretching modes [25] and are characteristic of cinnabar pigments.

At this point, Raman measurements were also carried out on the pigments painted on the tablets to identify their composition in terms of chemical configurations. However, no clear Raman signals were collected. This result is in good agreement with previously reported analyses of natural and synthetic dyes found in textiles, inks and paints. The low Raman scattering crosssections and the significant fluorescent background put severe limits on the quality of Raman spectra [26], [27].

In order to overcome these limitations, we used surfaceenhanced Raman scattering (SERS). It is well known that Raman cross-sections of molecules adsorbed on artificially roughened noble metal surfaces show dramatic enhancements thanks to the amplification of the incident field produced by the excitation of the localised plasmon resonance modes corresponding to the metallic nanostructure. Thus, we expected that this approach could be effective for characterising the pigments present on the tablets. Raman spectra acquired from the powder of commercial dyes were used as a reference for SERS measurements carried out on the painted tablets.

In particular, the SERS behaviour of two dyes of interest in the cultural heritage field, alizarin and purpurin, adsorbed on gold nanostructured substrates were analysed. Their molecular structures are similar except for the presence of an additional hydroxy group in purpurin. Figure 9 shows the chemical structure of alizarin and purpurin (panels a and d), a scanning electron microscope image of the surface morphology of the gold nanostructured film used for SERS, characterised by islands (agglomerates) with smooth edges (panel b) and the Raman spectra acquired from the surface of substrates soaked in the alizarin and purpurin aqueous solutions (panels $\mathrm{c}$ and e). The spectra acquired from the bare glass substrate show no evidence of Raman peaks related to the presence of dyes. In contrast, SERS spectra obtained from the surface of the gold-covered substrates show clear Raman contributions typical of the investigated dyes [28], [29]. The precise SERS spectra acquired from the powders gave us hope for similar results from the a)

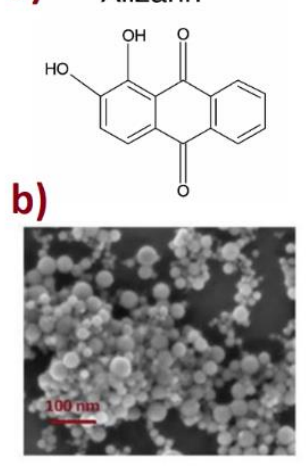

d)

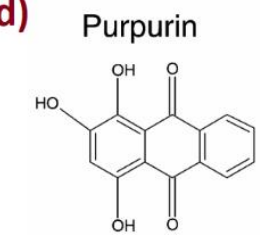

c)

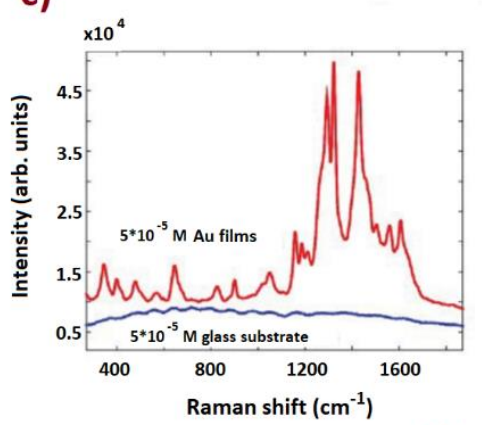

e)

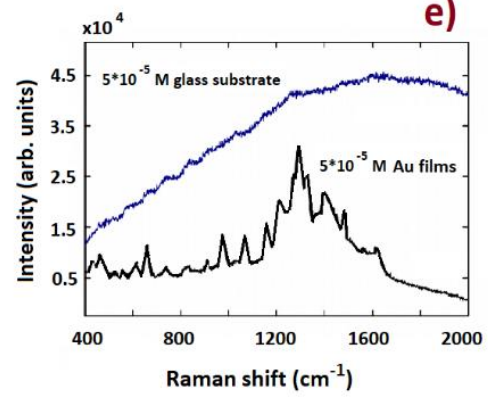

Figure 9. a, d) Chemical structure of alizarin and purpurin, b) SEM image of the synthesised gold film, c, e) Raman spectra of alizarin and purpurin powders adsorbed on the surface of Au nanostructured substrate.

tablets. Therefore, we proceeded to collect the Raman spectra from the wooden support, which had previously been prepared using Firenze Zecchi pigments, covered with gold colloid and then air-dried before Raman analyses were carried out. Using the SERS approach, it was possible to identify different red pigments (alizarin, purpurin, madder lake, lac and ochre) and white lead, whose Raman features are shown in Figure 10 and Figure 11, respectively.

The Raman spectra in Figure 10a show the characteristic vibrational bands of both alizarin and purpurin. Alizarin peaks are located at about 580 (skeletal vibrations), 1015 (C-C stretching, C-C-C bending), 1185 (C-C stretching, C-H and C-CC bending), 1285 (C-O and $\mathrm{C}-\mathrm{C}$ stretching) and 1558 (C-C stretching) $\mathrm{cm}-1$, while those centred at about 740, 980, 1027, 1218 and $1398 \mathrm{~cm}^{-1}$ nearly coincide with purpurin features [30],

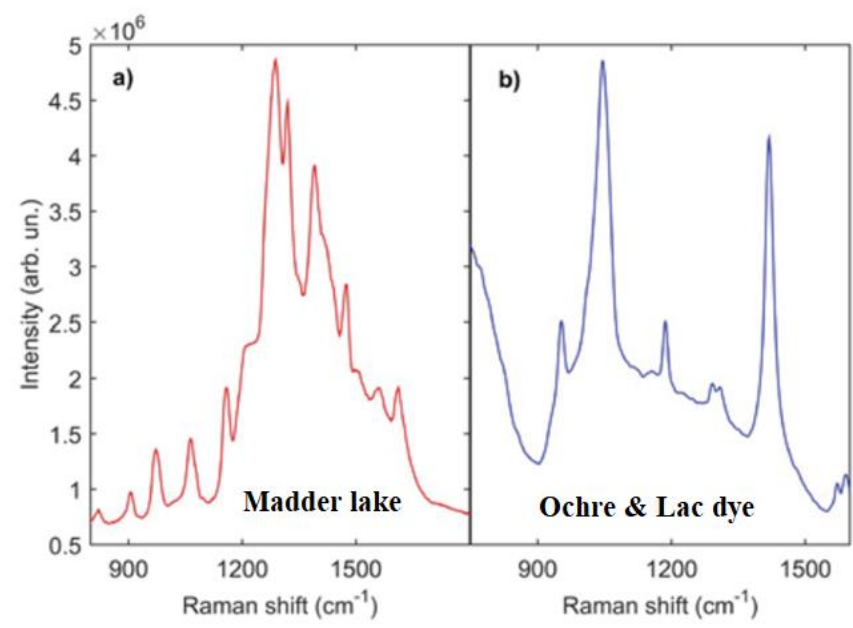

Figure 10. Raman spectra of (a) madder lake (which contains both alizarin and purpurin) and (b) ochre/lac on painted tablets covered with gold nano colloids and then dried in air. 


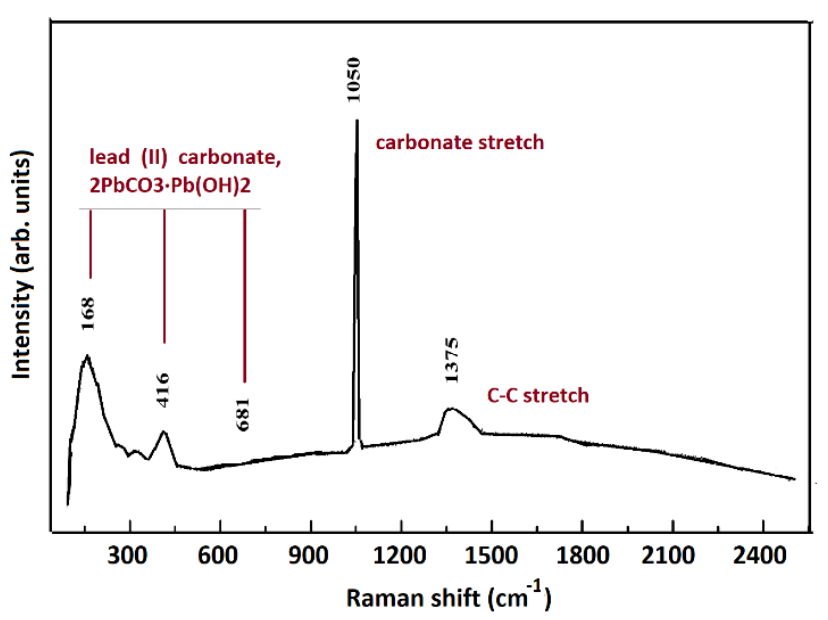

Figure 11. Raman spectra of white lead pigment on the painted tablet covered with gold nano colloids and then dried in air. Raman modes of hydrated calcium sulphate and carbonate modes, such as those of $2 \mathrm{PbCO} 3$, can be identified.

[31]. Thus, the madder lake dye was correctly identified by SERS, as was the mixture of red ochre and Lac dyes (see Figure 10b) that had been brushed on the wooden tablets. Finally, the SERS spectra shown in Figure 11 nearly coincide with those of gypsum (hydrated calcium sulphate), whose Raman bands are generally located at about 181, 415, 493, 617, 670, 1008 and $1134 \mathrm{~cm}^{-1}$, and those of a carbonate material (i.e. $2 \mathrm{PbCO} 3$ ) [32]. Ultimately, all of the pigments present on the wooden tables were correctly identified, confirming the reliability of the MSCT data.

\section{CONCLUSIONS}

For the first time, clinical MSCT was applied to the investigation of pigments painted on a wooden support. The presented results indicate that MSCT is a valuable and promising diagnostic method for the analysis of painted objects [33]. MPR and VRT post-processing techniques make it possible to 'dissect' the wood without contact, allowing for a complete analysis. Moreover, MSCT can be adapted for the non-destructive characterisation of coatings and coating pigments, which can be differentiated based on Hounsfield units obtained from a linear transformation of the measured attenuation coefficients. The only drawback - the inability to recognise organic pigments was overcome in this work by associating the results of the Raman/SERS scans with the MSCT ones. Then, by combining $\mathrm{X}$-ray densitometric and SERS measurements, it was possible to identify and characterise both inorganic and organic materials present on the wooden tablets. These techniques can be extended to the investigation of other objects of interest in cultural heritage, and prospective studies will continue to explore and refine the method.

\section{ACKNOWLEDGEMENT}

The authors would like to thank Full Prof. Marcello Longo of the Policlinico G. Martino of Messina, Italy.

\section{REFERENCES}

[1] L. Bonizzoni, S. Bruni, M. Gargano, V. Guglielmini, C. Zaffino, A. Pezzotta, A. Pilato, T. Auricchio, L. Delvaux, N. Ludwig, Use of integrated non-invasive analyses for pigment characterisation and indirect dating of old restorations on one Egyptian coffin of the XXI dynasty, Microchemical Journal 138 (2018), pp. 122-131. DOI: 10.1016/j.microc.2018.01.002

[2] C. Denoël, P. Roger Puyo, A. M. Brunet, N. P. Siloe, Illuminating the Carolingian era: discoveries as a result of scientific analyses, Heritage Science 6(1) (2018), art. 28.

DOI: $10.1186 / \mathrm{s} 40494-018-0194-1$

[3] M. Mantler, M. Schreiner, X-ray fluorescence spectrometry in art and archaeology, X-ray Spectrometry 29(1) (2000), pp. 3-17. DOI: $\quad 10.1002 /($ SICI) $1097-4539(200001 / 02) 29: 1<3::$ AID XRS398 $>3.0 . \mathrm{CO} ; 2-\mathrm{O}$

[4] J. Wouters, A. Verhecken, The coccid insect dyes: HPLC and computerised diode-array analysis of dyed yarns, Stud. Conserv. 34 (1989), p. 189.

DOI: $\underline{10.2307 / 1506286}$

[5] L. H. Oakley, S. A. Dinehart, S. A. Svoboda, K. L. Wustholz, Identification of organic materials in historic oil paintings using correlated extraction less surface-enhanced Raman scattering and fluorescence microscopy, Anal. Chem. 83 (2011), p. 3986. DOI: $10.1021 / \mathrm{ac} 200698 \mathrm{q}$

[6] E. Fazio, F. Neri, A. Valenti, P. M. Ossi, S. Trusso, R. C. Ponterio, Raman spectroscopy of organic dyes adsorbed on pulsed laser deposited silver thin films, Appl. Surf. Sci. 278 (2013), pp. 259264.

DOI: $10.1016 /$ j.apsusc. 2012.10 .133

[7] C. Parisi, C. Pelosi, U. Santamaria, P. Pogliani, G. Agresti, S. Longo, The conservation project of a liturgical object: The case of infant Jesus of Prague in the church of Saint Mary of providence at Macchia Giarre (Italy), European Journal of Science and Theology 12(2) (2016), pp. 235-244.

[8] S. Longo, E. M. Mormina, F. Granata, D. Mallamace, M. Longo, S. Capuani, Investigation of an Egyptian mummy board by using clinical multislice computed tomography, Studies in Conservation 63(7) (2018), pp. 383-390.

DOI: $\underline{10.1080 / 00393630.2018 .1439805}$

[9] C. Cennini, Il Libro dell'Arte, F. Frezzato (editor), Neri Pozza, Milan, 2009, ISBN 978-88-730-5910-4.

[10] Zecchi Firenze. Online [Accessed 23 March 2021] http://www.zecchi.it

[11] E. Neri, P. Mareschi, D. Caramella, Produrre ed Elaborare Immagini Diagnostiche, C. Bartolozzi (editor), Springer, Milano, 2008, ISBN 978-88-470-1063-5.

[12] L. W. Goldman, Principles of CT: multislice CT, Journal of Nuclear Medicine Technology 36(2) (2008), pp. 57-68. DOI: $10.2967 /$ inmt.107.044826

[13] L. O. Lindgren, Medical CAT-scanning: X-ray absorption coefficients, CT-numbers and their relation to wood density, Wood Science and Technology 25(5) (1991), pp. 341-349. DOI: $10.1007 / \mathrm{BF} 00226173$

[14] M. Tommasini, C. Zanchi, A. Lucotti, E. Fazio, M. Santoro, S. Spadaro, F. Neri, S. Trusso, E. Ciusani, U. de Grazia, M. Casazza, P. M. Ossi, Laser synthesised nanoparticles for therapeutic drug monitoring, in: Advances in the Application of Lasers in Materials Science. P. M. Ossi (editor). Springer, Cham, 2018, ISBN 978-3030-07261-2, pp. 339-360.

[15] Mineralogy Database. Online [Accessed 23 March 2021] http://webmineral.com/

[16] M. C. Caggiani, A. Cosentino, A. Mangone, Pigments Checker version 3.0, a handy set for conservation scientists: a free online Raman spectra database, Microchemical Journal 129 (2016), pp. 123-132.

DOI: $10.1016 /$ j.microc. 2016.06.020

[17] J. Bill, K. Dalen, A. Daly, Ø. Johnsen, Dendro CT dendrochronology without damage, Dendrochronologia 30 (2012), pp. 223-230.

DOI: $10.1016 /$ j.dendro.2011.11.002

[18] S. Berti, A. Crivellaro, M. Nocetti, L. Rescic, L. Sozzi, Conoscere il Legno, CNR IVALSA, Tolmezzo, 2007.

[19] H. N. Lioe, D. R. Adawiyah, R. Anggraeni, Isolation and characterization of the major natural dyestuff component of 
Brazilwood (Caesalpinia sappan L.), International Food Research Journal 19(2) (2012), p. 537.

[20] M. V. Canamares, J. V. Garcia-Ramos, C. Domingo, S. SanchezCortes, Surface Enhanced Raman scattering study of the anthraquinone red pigment carminic acid, Vibrational Spectroscopy 40 (2006), p. 161

DOI: $10.1016 / j$.vibspec.2005.08.002

[21] Database of ATR-FT-IR spectra of various materials: Lead white. Online [Accessed 23 March 2021]

http://lisa.chem.ut.ee/IR spectra/paint/pigments/lead-white/

[22] Database of ATR-FT-IR spectra of various materials: Verdigris. Online [Accessed 23 March 2021]

http://lisa.chem.ut.ee/IR spectra/paint/pigments/verdigris/

[23] Database of ATR-FT-IR spectra of various materials: Cinnabar. Online [Accessed 23 March 2021] http://lisa.chem.ut.ee/IR spectra/paint/pigments/cinnabar/

[24] R. L. Frost, W. N. Martens, L. Rintoul, E. Mahmutagic, J. T. Kloprogge, Raman spectroscopy of the basic copper phosphate minerals cornetite, libethenite, pseudomalachite, reichenbachite and ludjibaite, Journal of Raman Spectroscopy 33(4) (2002), pp. 252-259.

DOI: $10.1016 /$ S1386-1425(02)00034-3

[25] E. Mattei, G. Vivo, A. Santis, C. Gaetani, C. Pelosi, U. Santamaria, Raman spectroscopic analysis of azurite blackening, Journal of Raman Spectroscopy 39 (2008), pp. 302-306.

DOI: $\underline{10.1002 / \text { irs. } 1845}$

[26] L. Burgio, R. J. H. Clark, S. Firth, Raman spectroscopy as a means for the identification of plattnerite (PbO2), of lead pigments and of their degradation products, Analyst 126 (2001), pp. 222-227. DOI: $10.1039 / \mathrm{b} 008302 j$

[27] R. L. Frost, W. N. Martens, L. Rintoul, E. Mahmutagic, J. T. Kloprogge, Raman spectroscopic study of azurite and malachite at 298 and 77, Journal of Raman Spectroscopy 10 (2002), pp. 469-
480.

DOI: $\underline{10.1002 / \text { jrs. } 848}$

[28] F. Casadio, M. Leona, J. R. Lombardi, R. Van Duyne, Identification of organic colorants in fibers, paints, and glazes by surface enhanced Raman spectroscopy, Accounts of Chemical Research 43 (2010), p. 782. DOI: $10.1021 / \operatorname{ar} 100019 \mathrm{q}$

[29] M. Bonelli, A. Miotello, P. Mosaner, C. Casiraghi, P. M. Ossi, Pulsed laser deposition of carbon films: tailoring structure and properties, Journal of Applied Physics 93 (2003), p. 859. DOI: $10.1007 / 11378235 \quad 18$

[30] A. V. Whitney, R. P. Van Duyne, F. Casadio, An innovative surface-enhanced Raman spectroscopy (SERS) method for the identification of six historical lakes and dyestuffs, Journal of Raman Spectroscopy 37 (2006), p. 993. DOI: $10.1002 /$ irs. 1576

[31] M. A. García-Bucio, E. Casanova-González, J. L.Ruvalcaba-Sil, E. Arroyo-Lemus, A. Mitrani-Viggiano, Spectroscopic characterisation of sixteenth-century panel painting references using Raman, surface-enhanced Raman spectroscopy and heliumRaman system for in situ analysis of Ibero-American Colonial paintings, Phil. Trans. R. Soc. A 374(2082) (2016), 20160051. DOI: $10.1098 /$ rsta.2016.0051

[32] J. H. Hubbel, S. M. Seltzer, X-ray mass attenuation coefficients, NIST Standard Reference Database 126, 2004.

DOI: $\underline{10.18434 / \mathrm{T} 4 \mathrm{D} 01 \mathrm{~F}}$

[33] L. Montaina, S. Longo, G. Galotta, G. Tranquilli, R. Saccuman, S.Capuani, Assessment of the Panel Support of a SeventeenthCentury Dutch Painting by Clinical Multislice Computed Tomography, Studies in Conservation 66(3) (2021), pp. 174-181. DOI: $\underline{10.1080 / 00393630.2020 .1757881}$ 